\title{
COMPARISON OF PLANT FUNCTIONAL TRAITS BETWEEN WILD AND REINTRODUCED SINOJACKIA HUANGMEIENSIS, A RARE AND ENDANGERED PLANT
}

\author{
REN, Z. K. ${ }^{1}-$ WANG, S. T. ${ }^{2}-$ YANG, $^{2}{ }^{2}-$ JIANG, M. X. $.^{2 *}-$ DU, K. B..$^{*}$ \\ ${ }^{1}$ College of Horticulture and Forestry Sciences, Huazhong Agricultural University, Wuhan \\ 430070, Hubei, China \\ ${ }^{2}$ Key Laboratory of Aquatic Botany and Watershed Ecology, Wuhan Botanical Garden, Chinese \\ Academy of Sciences, Wuhan 430074, China \\ *Corresponding authors \\ e-mail:mxjiang@wbgcas.cn; kebingdu@mail.hzau.edu.cn
}

(Received $29^{\text {th }}$ May 2021; accepted $4^{\text {th }}$ Sep 2021)

\begin{abstract}
Sinojackia huangmeiensis is a rare and endangered plant in China. To help protect S. huangmeiensis, we have implemented its reintroduction via augmentation and translocation. Here, we compared the morphological, anatomical, and ecophysiological traits of leaves of wild and reintroduced (augmented and translocated) plants. Leaf thickness, leaf area, and dry matter content of the trunk leaves were highest for augmented plants, intermediate for wild plants, and lowest for translocated plants. Specific leaf area of the trunk leaves was largest for translocated plants, intermediate for wild plants, and smallest for augmented plants. The ratio of palisade tissue to spongy tissue in trunk leaves was lower in both augmented plants and translocated plants than in wild plants. The maximum photosynthetic rate of augmented and translocated plants was similar and higher than that of wild plants. Water-use efficiency was highest for wild plants and lowest for augmented plants. We found that S. huangmeiensis was a mesophyte. It could tolerate a wide range of light conditions and had strong ecophysiological adaptability. Our findings suggest that $S$. huangmeiensis, and perhaps other endangered plants that have narrow distributions and that produce sprouts, can be transplanted with trunk and sprouts together in order to increase their survival.
\end{abstract}

Keywords: ecophysiological traits, mesophyte, morphological and anatomical traits, sprout, augmentation, translocation

\section{Introduction}

With population growth and urbanization, human activities directly and indirectly have led to a heightened risk of extinction for about $20 \%$ of plants in the world (Sharrock and Wyse Jackson, 2017). In China, about 12\% of the 35000 species of higher plants (bryophytes, ferns and seed plants) are under threat (Qin and Zhao, 2017). Because these threatened plants are important parts of ecosystems, they require conservation.

There are three approaches to plant conservation: in situ conservation, ex situ conservation, and reintroduction. Reintroduction is the deliberate establishment of individuals of a species in an area or habitat where it has become extirpated with the aim of establishing a viable, self-sustaining population. Plant reintroduction can involve the establishment of an extirpated species in a relatively intact habitat or it can be part of the restoration of a degraded habitat (Maunder, 1992). As a conservation measure, reintroduction is more effective than simple in situ conservation and single ex situ conservation, and can save and protect extremely small populations of wild plants (Yang et al., 2020). The three types of reintroduction include augmentation (adding 
more individuals to an existing population), restitution or reintroduction (reintroducing individuals to a population that has disappeared in an area), and translocation (Liu et al., 2015; Ren, 2020). While augmentation and reintroduction increase the abundance of the species in the native area, translocation can introduce the species to a new area. To date, more than 1000 plant reintroduction studies have been reported in the world. These studies have investigated physiological ecology, morphological anatomy, and functional traits (Catoni and Gratani, 2013); population dynamics, genetic diversity, and population persistence (Maschinski and Haskins, 2012; Taylor et al., 2017; Ren, 2020); and levels from the organ to the individual, population, metapopulation, and ecosystem (Seddon, 2010; Godefroid and Vanderborght, 2011). The main reproductive materials used in plant reintroductions are seeds, seedlings, grafted seedlings, cutting seedlings, tissue culture seedlings, and rarely, sprouting seedlings (Bond and Midgley, 2001; Ren, 2020).

Some woody plants can also regenerate naturally by producing seeds and by sprouting ( $\mathrm{Lu}$ et al., 2020). Sprouting can increase the stability of plant populations under adversity (del Tredici, 2001; Lu et al., 2020). Researchers have speculated that the production of multiple sprouts by one root system increases a plant's ability to resist competition and herbivory early in the regeneration process (Pigott, 1989; Lu et al., 2020). The survival and growth of sprouts are affected by canopy tree species and microhabitat properties (Ahrens and Newton, 2008). For understory plants, basal sprouting is an important mechanism for promoting both survival under closed-canopy conditions and vegetative expansion when a canopy gap develops. At exposed sites or near the limits of a species range, the production of basal sprouts allows plants to spread into adjacent areas, thereby circumventing the difficult process of seedling establishment (Del Tredici, 2001).

Sinojackia huangmeiensis is a small deciduous tree or shrub in the family Styracaceae. It has a high ornamental value because of its flowers and fruit (Fig. 1). It is endemic to China and its wild individuals are currently distributed only in the secondary forest in the Longganhu National Wetland Nature Reserve, Huangmei County, Hubei Province (Wang et al., 2018). The distribution of $S$. huangmeiensis is narrow, with an area of only about 0.33 ha. Because of habitat destruction, logging, termite grazing, hard peel of fruits, and poor germination, only 501 individuals have been found in the field, and these face a high risk of extinction (Wei et al., 2018). S. huangmeiensis is a rare and endangered species and is listed as one of the 120 plant species with extremely small populations in China (Wang et al., 2018).
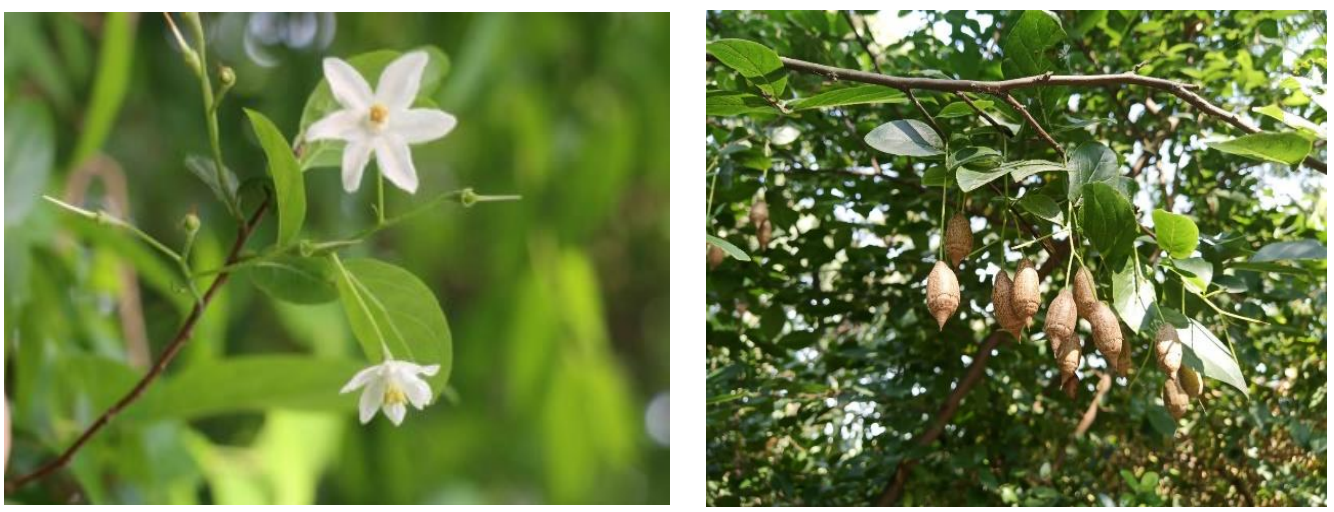

Figure 1. The flowers and fruits of Sinojackia huangmeiensis 
Previous studies have shown that the wild population of $S$. huangmeiensis can naturally recruit new individuals, but its age structure includes only a low proportion of young individuals, and every wild individual produces sprouts (Wang et al., 2018). The population has a clustered distribution (Luo et al., 2016), and its genetic diversity is low (Ruan et al., 2012; Zhao et al., 2016; Gao et al., 2018; Dong et al., 2020). In the same community, the leaf functional traits of $S$. huangmeiensis vary among different microhabitats (Wang et al., 2019). The seed setting rate and germination rate of S. huangmeiensis are very low (Zhang et al., 2008). However, it can be propagated via cuttings. The fruit size of the wild $S$. huangmeiensis plants is similar to that of ex situ conserved plants (Liu et al., 2018). To date, there have been no reintroduction studies of $S$. huangmeiensis, or studies that have compared the morphological, anatomical, and ecophysiological traits of wild plants and reintroduced plants (including sprouts). Investigation of these variables should help explain the success or failure of $S$. huangmeiensis reintroduction and the plant's potential adaptive mechanisms.

In this study of $S$. huangmeiensis, we compared the morphological, anatomical, and ecophysiological traits of wild plants, augmented plants, and translocated plants. We attempted to answer the following three questions: (1) Does $S$. huangmeiensis have a wide or narrow range of light intensity preference? (2) How do the morphological, anatomical, and ecophysiological traits of leaves differ between "trunk leaves" (those that extend from the trunk) and "sprout leaves" (those that extend from sprouts)? and (3) To what extent are reintroduced plants ecologically adaptable? The results should provide useful information for the protection and utilization of S. huangmeiensis.

\section{Materials and methods}

\section{Study area}

The study was concurrently conducted at three sites. The first site was the core area of the Longanhu National Nature Reserve, Huangmei County, Hubei Province, central China $\left(29^{\circ} 59^{\prime} \mathrm{N}, 116^{\circ} 01^{\prime} \mathrm{E}\right.$, hereafter referred to as LGH or the wild population site). LGH is an original distribution area of $S$. huangmeiensis. It has a subtropical monsoon climate, with a mean annual temperature of $17.3^{\circ} \mathrm{C}$ and a total annual rainfall of $1431 \mathrm{~mm}$. The altitude is about $31 \mathrm{~m}$. LGH has a red soil, and its climax plant community is subtropical evergreen broad-leaved forest (Liu et al., 2018). The second site was at the experimental area of the Longanhu National Nature Reserve (hereafter referred to as AUG or the augmentation site). Augmentation was conducted to increase the number of individuals near the wild population, and these individuals were derived from cuttings from different wild individuals so as to provide genetic diversity. The distance between the core area and experimental area was about $300 \mathrm{~m}$. The third site was at the Wuhan Botanical Garden $\left(30^{\circ} 32^{\prime} \mathrm{N}, 14^{\circ} 24^{\prime} \mathrm{E}\right.$, hereafter referred to as WBG or the translocation site), Wuhan City, Hubei Province, China. WBG is about $200 \mathrm{~km}$ from the original distribution area of $S$. huangmeiensis. It also has a subtropical monsoon climate, with a mean annual temperature of $17.1^{\circ} \mathrm{C}$ and a total annual rainfall of $1308 \mathrm{~mm}$. The altitude is about $80 \mathrm{~m}$. WBG has a red soil (Liu et al., 2018). The climate at WBG is colder and dryer than that at LGH and AUG. We hoped to successfully translocate $S$. huangmeiensis to WBG in order to establish a new population and also to enable the assessment of climate effects on this species. 


\section{Sample plant selection}

In August 2020, three wild plants (including sprouts) were selected at the LGH site, and three augmented plants were selected at the AUG site; the latter augmented plants were 3 years old and were derived from cuttings. The augmented plants were also watered in the dry season and fertilized once each year. Three translocated plants (including sprouts) were selected at the WBG site; these translocated plants were 10 years old cuttings seedlings planted under the plantation canopy and that were growing naturally without a fence (Fig. 2).
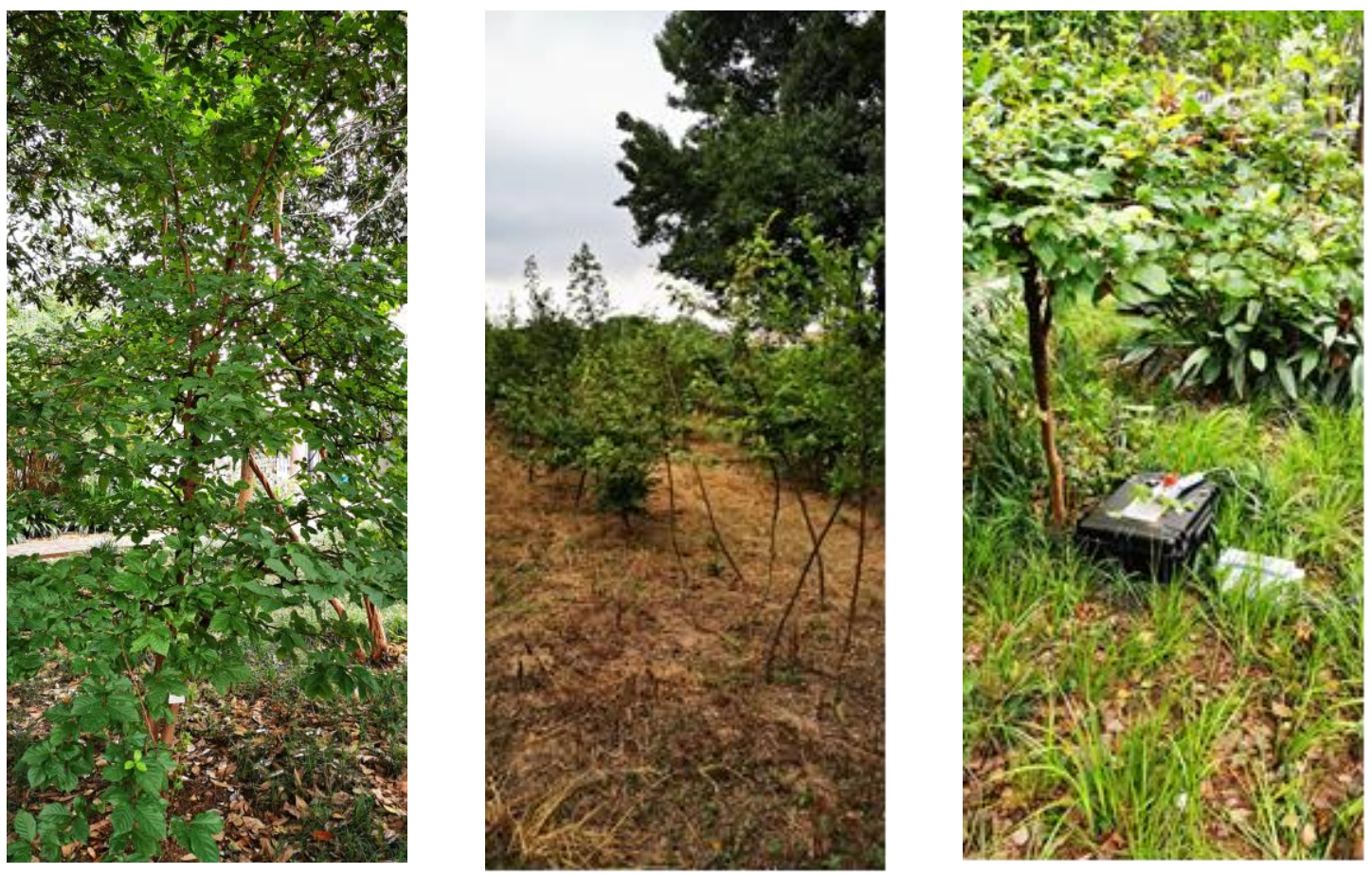

Figure 2. The habitat of wild, augmented, and translocated S. huangmeiensis plants at three sites (From left to right)

The height, diameter at breast height, trunk diameter at the soil surface, and crown width of each of the nine $S$. huangmeiensis trees were measured in the field, and the numbers of sprouts were counted. The habitat characteristics of the sites and the plant traits are listed in Table 1.

\section{Measurement of morphological and anatomical traits}

In August 2020, we counted the sprouts and fruits for each of the three $S$. huangmeiensis trees at each site, and we used a Vernier caliper to measure the diameter of 10 fruits from each tree. A Vernier caliper was also used to measure the thickness of 10 leaves from each trunk and sprout of each tree at each site. We also collected 20 mature leaves from the trunk and one sprout of each S. huangmeiensis plant; these were transported in an ice chest to the laboratory where leaf area, leaf dry matter content, specific leaf area, and the thickness of palisade tissue and spongy tissue were measured; tissue thickness was measured by making freehand slices (Soudzilovskaiaa et al., 2013; Ren et al., 2019). 
Table 1. The habitat and description of wild, augmented, and translocated S. huangmeiensis plants at three sites. Values are means $+S D$ of three trees per site

\begin{tabular}{c|c|c|c}
\hline \multirow{2}{*}{ Variable } & \multicolumn{3}{|c}{ Site } \\
\cline { 2 - 4 } & LGH (wild plants) & AUG (augmented plants) & WBG (translocated plants) \\
\hline Vegetation & $\begin{array}{c}\text { Secondary forest } \\
\text { Cinnamomum camphora }\end{array}$ & Field & Plantation \\
Dominant species & $\begin{array}{c}\text { L.) Presl, Pinus elliottii, } \\
\text { Magnolia zenii Cheng } \\
\text { Light transmittance (\%) }\end{array}$ & - & $\begin{array}{c}\text { Quercus acutissima, Ilex } \\
\text { cornuta, Celtis sinensis }\end{array}$ \\
Soil type & $9.2 \pm 2.9$ & $100 \pm 0$ & $8.2 \pm 1.6$ \\
Number of individuals & Red soil & Red soil & Red soil \\
measured & 3 & 3 & 3 \\
Age (years) & - & 3 & 10 \\
Diameter at breast & & $2.9 \pm 0.4$ & $5.8 \pm 1.5$ \\
height (cm) & $5.6 \pm 1.3$ & $4.6 \pm 0.6$ & $7.1 \pm 2.0$ \\
Trunk diameter (cm) & $7.1 \pm 2.3$ & $2.2 \pm 0.3$ & $2.6 \pm 0.6$ \\
Height (m) & $3.2 \pm 0.7$ & &
\end{tabular}

\section{Measurement of ecophysiological traits}

The light saturation point (LSP), light compensation point (LCP), light-saturated net photosynthetic rate (Pmax), dark respiration rate (RD), and water-use efficiency (WUE) were measured on one mature leaf of the trunk and one mature leaf of a sprout of each of the three trees at the LGH, AGU, and WBG sites. A portable photosynthesis apparatus (Lci-T, Bioscientific Ltd., UK) was used to measure the light response curves of leaves on a sunny morning between 8:30 and 12:00 am in August 2020. The chamber temperature was set at $25^{\circ} \mathrm{C}$ and the reference $\mathrm{CO}_{2}$ concentration was set at $400 \mu \mathrm{mol}$ $\mathrm{mol}^{-1}$, which were similar to the ambient environment. In order from strong to weak, the light intensity was manually set at 1600, 1400, 1200, 1000, 800, 600, 400, 200, 100, 50, 20, and $0 \mu \mathrm{mol} \cdot \mathrm{m}^{-2} \cdot \mathrm{s}^{-1}$ (Nijs et al., 1997; Dubois et al., 2007; Wang et al., 2016).

We harvested 10 more mature leaves from each of the three trees at each site to analyze leaf pigment contents. Leaf discs $(0.6 \mathrm{~cm}$ in diameter) were immersed in $80 \%$ acetone and were kept in the dark at $4^{\circ} \mathrm{C}$ for $5 \mathrm{~d}$. The light absorption of the extract was measured at 663, 645, and $440 \mathrm{~nm}$ with a UV-visible spectrophotometer (UV-3802, Unico, China), and the contents of chlorophyll a ( $\mathrm{Chl} \mathrm{a}$ ), chlorophyll b (Chl b), and carotenoids (Car) were calculated. The ratio of chlorophyll a / b and the ratio of carotenoids to chlorophyll (Car / Chl) were also calculated (Wang et al., 2016).

\section{Measurement of light transmittance under the forest canopy}

The light transmittance under the forest canopy was also measured at each site. Because of the great heterogeneity of light under the forest canopy, the Digital Lux Meter (TES 1332a, Taiwan, China) was used to measure the light intensity outside the forest and at 9 points under the forest canopy. The light transmittance (\%) was calculated from the light intensity under the forest canopy and the light intensity outside the forest (Ouyang et al., 2021). 


\section{Statistical analysis}

We used one-way analysis of variance (ANOVA) to test the differences in the leaf functional traits (i.e., morphological, anatomical, and ecophysiological traits) among the wild, augmented, and translocated $S$. huangmeiensis plants. We used a paired-sample ttest to compare traits between the leaves on the trunk vs. leaves on the sprout; this was done separately for the wild site and the reintroduction site. Statistical significance was set at $\mathrm{P}<0.05$. Unless noted otherwise, means and standard deviations (SD) are presented. All analyses were conducted using the statistical program SPSS 25.0 (IBM Inc., Chicago, USA) and Excel 2003.

\section{Results}

\section{Comparison of functional traits of trunk leaves at three sites}

There were significant differences in morphological and anatomical traits among wild, augmented, and translocated plants (Table 2). The leaf thickness, area, and dry matter content of the trunk leaves were highest for augmented plants, intermediate for wild plants, and lowest for translocated plants. The specific leaf area of the trunk leaves was highest for translocated plants, intermediate for wild plants, and lowest for augmented plants. The ratio of palisade tissue to spongy tissue in trunk leaves was higher for wild plants than for augmented or translocated plants.

Table 2. Morphological and anatomical properties of Sinojackia huangmeiensis at three sites

\begin{tabular}{|c|c|c|c|}
\hline \multirow{2}{*}{ Property } & \multicolumn{3}{|c|}{ Site } \\
\hline & LGH (wild plants) & AUG (augmented plants) & WBG (translocated plants) \\
\hline Leaf thickness (mm) & $0.156 \pm 0.015^{\mathrm{b}}$ & $0.200 \pm 0.015^{\mathrm{a}}$ & $0.128 \pm 0.008^{c}$ \\
\hline Leaf area $\left(\mathrm{cm}^{2}\right)$ & $24.80 \pm 2.60^{b}$ & $28.12 \pm 1.89^{\mathrm{a}}$ & $15.96 \pm 0.61^{\mathrm{c}}$ \\
\hline $\begin{array}{l}\text { Leaf dry matter content } \\
\qquad\left(\mathrm{mg} \mathrm{g}^{-1}\right)\end{array}$ & $321.02 \pm 47.58^{b}$ & $388.86 \pm 11.19^{\mathrm{a}}$ & $260.34 \pm 13.54^{\mathrm{c}}$ \\
\hline Specific leaf area $\left(\mathrm{cm}^{2} \cdot \mathrm{g}\right.$ & $23.05 \pm 6.11^{\mathrm{b}}$ & $11.89 \pm 0.31^{\mathrm{c}}$ & $35.90 \pm 3.15^{\mathrm{a}}$ \\
\hline $\begin{array}{c}\text { Thickness of palisade } \\
\text { tissue }(\mu \mathrm{m})\end{array}$ & $48.04 \pm 11.41^{\mathrm{b}}$ & $60.19 \pm 16.26^{\mathrm{a}}$ & $29.30 \pm 3.80^{c}$ \\
\hline $\begin{array}{c}\text { Thickness of spongy } \\
\text { tissue }(\mu \mathrm{m})\end{array}$ & $46.90 \pm 9.41^{\mathrm{b}}$ & $73.95 \pm 14.79^{\mathrm{a}}$ & $39.17 \pm 2.03^{\mathrm{c}}$ \\
\hline $\begin{array}{l}\text { Palisade tissue/spongy } \\
\text { tissue }\end{array}$ & $1.02 \pm 0.78^{\mathrm{a}}$ & $0.81 \pm 0.53^{b}$ & $0.75 \pm 0.13^{b}$ \\
\hline $\begin{array}{l}\text { Number of sprouts } \\
\quad \text { (individual) }\end{array}$ & $21 \pm 6^{\mathrm{a}}$ & $0 \pm 0^{\mathrm{c} \#}$ & $6 \pm 4^{b}$ \\
\hline $\begin{array}{l}\text { Number of fruits } \\
\text { (individual) }\end{array}$ & $79 \pm 19^{b}$ & $145 \pm 28^{a}$ & $37 \pm 2^{c}$ \\
\hline Diameter of fruit (mm) & $11.66 \pm 1.61^{\mathrm{b}}$ & $15.54 \pm 2.15^{\mathrm{a}}$ & $9.84 \pm 0.54^{\mathrm{c}}$ \\
\hline
\end{tabular}

Note: In this table, traits for leaves are based on trunk leaves. Values are means $\pm \mathrm{SE}, n=10$. \# means "Sprouts were cut off". Within each row, different lowercase letters indicate significant differences between sites at $P<0.05$ 
The number of sprouts was much higher for wild plants than for translocated or augmented plants. The number of fruits and the diameter of fruits of were largest for augmented plants, intermediate for wild plants, and smallest for translocated plants (Table 2).

Most of the ecophysiological traits of the trunk leaves significantly differed among wild, augmented, and translocated plants (Table 3). The $\mathrm{Chl} \mathrm{a} \mathrm{/} \mathrm{Chl} \mathrm{b} \mathrm{ratio} \mathrm{of} \mathrm{leaves} \mathrm{at}$ the three sites was > 3, and was highest for the augmented plants. The Car / Chl values of leaves at the three sites were generally similar. The light saturation point was highest for the augmented plants and was lowest for the wild plants. The light compensation point was lowest for translocated plants and highest for augmented plants. The maximum photosynthetic rate was similar for the augmented and translocated plants and was higher for the latter two kinds of plants than for the wild plants. The water-use efficiency was highest for the wild plants and lowest for the augmented plants.

Table 3. Ecophysiological traits of Sinojackia huangmeiensis leaves

\begin{tabular}{|c|c|c|c|}
\hline \multirow{2}{*}{ Trait } & \multicolumn{3}{|c|}{ Site } \\
\hline & LGH (wild plants) & AUG (augmented plants) & WBG (translocated plants) \\
\hline Chl $a\left(\mathrm{mg} \mathrm{g}^{-1}\right)$ & $2.46 \pm 0.04^{\mathrm{b}}$ & $1.49 \pm 0.09^{c}$ & $2.70 \pm 0.33^{\mathrm{a}}$ \\
\hline Chl $b\left(\mathrm{mg} \mathrm{g}^{-1}\right)$ & $0.53 \pm 0.04^{b}$ & $0.27 \pm 0.02^{\mathrm{c}}$ & $0.64 \pm 0.05^{\mathrm{a}}$ \\
\hline $\mathrm{Chl} \mathrm{a/Chl} \mathrm{b}$ & $4.64 \pm 0.04^{b}$ & $5.52 \pm 0.05^{\mathrm{a}}$ & $4.22 \pm 0.09^{c}$ \\
\hline $\operatorname{Car}\left(\mathrm{mg} \mathrm{g}^{-1}\right)$ & $0.68 \pm 0.03^{\mathrm{a}}$ & $0.41 \pm 0.02^{b}$ & $0.72 \pm 0.03^{a}$ \\
\hline Car/Chl & $0.23 \pm 0.01^{\mathrm{a}}$ & $0.23 \pm 0.01^{\mathrm{a}}$ & $0.22 \pm 0.01^{\mathrm{a}}$ \\
\hline $\operatorname{LSP}\left(\mu \mathrm{mol} \mathrm{m}{ }^{-2} \mathrm{~s}^{-1}\right)$ & $511.80 \pm 54.60^{\mathrm{c}}$ & $2245.07 \pm 784.02^{\mathrm{a}}$ & $948.70 \pm 412.00^{\mathrm{b}}$ \\
\hline $\mathrm{LCP}\left(\mu \mathrm{mol} \mathrm{m} \mathrm{m}^{-2} \mathrm{~s}^{-1}\right)$ & $21.23 \pm 4.05^{\mathrm{b}}$ & $37.36 \pm 0.44^{\mathrm{a}}$ & $17.48 \pm 7.41^{\mathrm{c}}$ \\
\hline$P_{\max }\left(\mu \mathrm{mol} \mathrm{m} \mathrm{m}^{-2} \mathrm{~s}^{-1}\right)$ & $5.14 \pm 1.54^{\mathrm{b}}$ & $6.01 \pm 0.76^{\mathrm{a}}$ & $6.04 \pm 1.58^{\mathrm{a}}$ \\
\hline$R_{\mathrm{D}}\left(\mu \mathrm{mol} \mathrm{m} \mathrm{m}^{-2} \mathrm{~s}^{-1}\right)$ & $3.39 \pm 0.56^{\mathrm{c}}$ & $3.72 \pm 0.25^{b}$ & $7.26 \pm 1.07^{\mathrm{a}}$ \\
\hline WUE $\left(\mu \mathrm{mol} \mathrm{mmol} \mathrm{m}^{-1}\right)$ & $138.87 \pm 19.81^{\mathrm{a}}$ & $79.81 \pm 0.88^{\mathrm{c}}$ & $105.31 \pm 21.26^{\mathrm{b}}$ \\
\hline
\end{tabular}

Note: In this table, traits for leaves are based on trunk leaves. Chl $a$ - chlorophyll $a$; Chl $b$ - chlorophyll $b$; Chl - chlorophyll. Car - carotenoid. LSP - light saturation point; LCP - light compensation point; $P_{\max }-$ maximum photosynthetic rate; $R_{\mathrm{D}}$ - dark respiration rate; WUE - water-use efficiency. Values are means $\pm \mathrm{SE}, n=3$. Within each row, different lowercase letters indicate significant differences between sites at $P<0.05$

\section{Comparison of functional traits of trunk leaves vs. sprout leaves}

For translocated plants, the leaf area, Car content, and Car/Chl were higher for trunk leaves than for sprout leaves $(\mathrm{P}<0.05)$; none of the other traits differed between trunk leaves and sprout leaves of translocated plants (Table 4). For wild plants, none of the morphological or ecophysiological traits significantly differed for trunk leaves vs. sprout leaves $(\mathrm{P}>0.05)$. 
Table 4. Comparisons of morphological and ecophysiological traits of trunk leaves vs. sprout leaves of Sinojackia huangmeiensis at a site with wild plants and at a site with translocated plants

\begin{tabular}{|c|c|c|c|c|}
\hline \multirow{2}{*}{ Variable } & \multicolumn{2}{|c|}{ LGH (wild plants) } & \multicolumn{2}{|c|}{ WBG (translocated plants) } \\
\hline & Trunk leaves & Sprout leaves & Trunk leaves & Sprout leaves \\
\hline Blade thickness (mm) & $0.16 \pm 0.01^{\mathrm{a}}$ & $0.10 \pm 0.01^{\mathrm{a}}$ & $0.13 \pm 0.01^{\mathrm{A}}$ & $0.11 \pm 0.01^{\mathrm{A}}$ \\
\hline Leaf area $\left(\mathrm{cm}^{2}\right)$ & $24.80 \pm 2.60^{\mathrm{a}}$ & $22.99 \pm 3.63^{\mathrm{a}}$ & $15.96 \pm 0.61^{\mathrm{A}}$ & $8.86 \pm 1.19^{\mathrm{B}}$ \\
\hline $\begin{array}{l}\text { Specific leaf area } \\
\qquad\left(\mathrm{cm}^{2} \cdot \mathrm{g}^{-1}\right)\end{array}$ & $23.05 \pm 6.11^{\mathrm{a}}$ & $25.67 \pm 8.05^{\mathrm{a}}$ & $35.90 \pm 3.15^{\mathrm{A}}$ & $48.83 \pm 3.65^{\mathrm{A}}$ \\
\hline $\begin{array}{l}\text { Leaf dry matter content } \\
\qquad\left(\mathrm{mg} \mathrm{g}^{-1}\right)\end{array}$ & $321.02 \pm 47.58^{\mathrm{a}}$ & $297.73 \pm 46.89^{a}$ & $260.34 \pm 13.54^{\mathrm{A}}$ & $167.58 \pm 18.59^{\mathrm{A}}$ \\
\hline $\operatorname{LSP}\left(\mu \mathrm{mol} \mathrm{m}{ }^{-2} \mathrm{~s}^{-1}\right)$ & $511.80 \pm 54.60^{\mathrm{a}}$ & $514.79 \pm 43.69^{\mathrm{a}}$ & $948.70 \pm 412.00^{\mathrm{A}}$ & $743.47 \pm 225.81^{\mathrm{A}}$ \\
\hline $\mathrm{LCP}\left(\mu \mathrm{mol} \mathrm{m}{ }^{-2} \mathrm{~s}^{-1}\right)$ & $21.23 \pm 4.05^{\mathrm{a}}$ & $16.85 \pm 2.37^{\mathrm{a}}$ & $17.48 \pm 7.41^{\mathrm{A}}$ & $15.10 \pm 2.14^{\mathrm{A}}$ \\
\hline$P_{\max }\left(\mu \mathrm{mol} \mathrm{m}{ }^{-2} \mathrm{~s}^{-1}\right)$ & $5.14 \pm 1.54^{\mathrm{a}}$ & $4.38 \pm 1.09^{\mathrm{a}}$ & $6.04 \pm 1.58^{\mathrm{A}}$ & $3.12 \pm 1.84^{\mathrm{A}}$ \\
\hline$R_{\mathrm{D}}\left(\mu \mathrm{mol} \mathrm{m}{ }^{-2} \mathrm{~s}^{-1}\right)$ & $3.39 \pm 0.56^{\mathrm{a}}$ & $5.28 \pm 1.57^{\mathrm{a}}$ & $7.26 \pm 1.07^{\mathrm{A}}$ & $3.55 \pm 1.52^{\mathrm{A}}$ \\
\hline WUE $\left(\mu \mathrm{mol} \mathrm{mmol}{ }^{-1}\right)$ & $138.87 \pm 19.81^{\mathrm{a}}$ & $93.26 \pm 9.56^{\mathrm{a}}$ & $105.31 \pm 21.26^{\mathrm{A}}$ & $69.20 \pm 20.98^{\mathrm{A}}$ \\
\hline Chl $a(\operatorname{mg~g}-1)$ & $2.46 \pm 0.04^{\mathrm{a}}$ & $2.32 \pm 0.48^{\mathrm{a}}$ & $2.70 \pm 0.33^{\mathrm{A}}$ & $1.40 \pm 0.11^{\mathrm{A}}$ \\
\hline $\mathrm{Chl} b\left(\mathrm{mg} \mathrm{g}^{-1}\right)$ & $0.53 \pm 0.04^{\mathrm{a}}$ & $0.58 \pm 0.12^{\mathrm{a}}$ & $0.64 \pm 0.05^{\mathrm{A}}$ & $0.60 \pm 0.10^{\mathrm{A}}$ \\
\hline $\operatorname{Car}\left(\mathrm{mg} \mathrm{g}^{-1}\right)$ & $0.68 \pm 0.03^{\mathrm{a}}$ & $0.60 \pm 0.12^{\mathrm{a}}$ & $0.72 \pm 0.03^{\mathrm{A}}$ & $0.18 \pm 0.00^{\mathrm{B}}$ \\
\hline Car/Chl & $0.23 \pm 0.01^{\mathrm{a}}$ & $0.21 \pm 0.01^{\mathrm{a}}$ & $0.22 \pm 0.01^{\mathrm{A}}$ & $0.09 \pm 0.01^{\mathrm{B}}$ \\
\hline
\end{tabular}

Note: Chl a - chlorophyll a; Chl b - chlorophyll b; Chl - chlorophyll. Car - carotenoid. LSP - light saturation point; LCP - light compensation point; Pmax - maximum photosynthetic rate; RD - dark respiration rate; WUE - water-use efficiency. Values are means $\pm \mathrm{SE}, \mathrm{n}=3$. For each trait within each site, different letters (lowercase for site LGH and uppercase for site WBG) indicate significant differences between trunk leaves vs. shoot leaves at $\mathrm{P}<0.05$

\section{Discussion}

\section{Sinojackia huangmeiensis tolerates a wide range of light intensities}

There were significant differences in morphological, anatomical, and ecophysiological traits among the three sites. The values for most of these traits tended to be highest for the wild plants (at site LGH), intermediate for the translocated plants (at site WBG), and lowest for the augmented plants (at site AUG). The results showed that wild, augmented, and translocated S. huangmeiensis plants can grow in an environment with 10-100\% light transmittance. This indicates that S. huangmeiensis can endure both shady and sunny conditions. In addition, the Chl a / Chl b values of the leaves at the three sites were greater than 3 , and the light compensation points were low, indicating that $S$. huangmeiensis is a mesophyte. These results are consistent with a previous report that found that $S$. huangmeiensis is shade tolerant but can also grow under strong light (Liang et al., 2007). Based on our results, we suggest that young seedlings or cuttings be kept in a shaded environment; once they are mature, these plants can be transplanted into a full-light environment. Light intensity does not influence plant's survival and distribution but influence plant's growth performance. 


\section{The distribution of Sinojackia huangmeiensis is narrow but its morphological, anatomical, and ecophysiological adaptability is substantial}

Sinojackia huangmeiensis showed strong morphological, anatomical, ecophysiological adaptability based on plant functional traits of wild and reintroduced (augmented and translocated) plants. Leaf thickness, leaf area, and dry matter content of the trunk leaves were highest for augmented plants, intermediate for wild plants, and lowest for translocated plants. Specific leaf area of the trunk leaves was largest for translocated plants, intermediate for wild plants, and smallest for augmented plants. The ratio of palisade tissue to spongy tissue in trunk leaves was lower in both augmented plants and translocated plants than in wild plants. The number and the diameter of fruits were largest in augmented plants, intermediate in wild plants, and lowest in translocated plants. The maximum photosynthetic rate of augmented and translocated plants was similar and higher than that of wild plants. Light saturation and compensation points were highest for augmented plants; the light saturation point was lowest for wild plants; and the light compensation point was lowest for translocated plants. Water-use efficiency was highest for wild plants and lowest for augmented plants. For translocated plants, leaf area, Car content, and Car/Chl were significantly higher for trunk leaves than for sprout leaves.

At the time of this study, a total of 501 wild individuals of $S$. huangmeiensis were growing naturally and with protection at the LGH site in the Longanhu National Nature Reserve. In the experimental area of the nature reserve (the AUG site), the augmented seedlings were continuously pruned, irrigated during droughts, and occasionally fertilized. According to genetic diversity data (Zhao et al., 2016; Gao et al., 2018; Dong et al., 2020), we selected 3 individuals from different genetic diversity groups for cuttings, and planted these cuttings at the AUG site, so as to achieve ex situ conservation of the full genetic diversity of this species. The temperature and rainfall were lower at the translocation site (the WBG site) than at the LGH site, but light transmittance was similar. The translocated plants grew well at the WBG site, and produced flowers, fruits, and sprouts. This indicates that $S$. huangmeiensis can survive and achieve asexual and sexual reproduction in Wuhan. We also introduced 3-year-old cutting seedlings with sprouts of $S$. huangmeiensis to Yantai, Shandong Province $\left(120^{\circ} 35^{\prime} \mathrm{E}, 37^{\circ} 26^{\prime} \mathrm{N}\right.$, total annual rainfall $=525 \mathrm{~mm}$, annual average temperature $\left.=13.4^{\circ} \mathrm{C}\right)$ and Guangzhou, Guangdong Province $\left(112^{\circ} 57^{\prime} \mathrm{E}, 23^{\circ} 35^{\prime} \mathrm{N}\right.$, total rainfall $=1612 \mathrm{~mm}$, annual average temperature $\left.=20.8^{\circ} \mathrm{C}\right)$; the plants survived in both places, but did not blossom or bear fruit in the past 3 years (unpublished data). Our findings suggest that $S$. huangmeiensis has strong adaptability and may survive under future climate conditions. Two other rare and endangered plants in South China, Manglietia longipedunculata and Euryodendron excelsum, also have narrow distribution ranges and strong ecophysiological adaptability (Ren et al., 2016, 2019). It is only because of their narrow distribution and human interference that they are endangered. The endangered state of these species could be relieved by their artificial reintroduction and translocation.

\section{For ex situ conservation and reintroduction, transplanting of the trunk and associated sprouts may improve the success rate}

Sinojackia huangmeiensis can simultaneously propagate via by producing seeds and by sprouting. Through sprouting regeneration, $S$. huangmeiensis is conducive to resist 
interference and adverse environment, and through both seedling and sprouting regeneration, $S$. huangmeiensis expands the distribution area. Thus, the natural regeneration of the population can be carried out normally (Wang et al., 2018).

Sprouting can increase the persistence of reintroduced plants. Sprout growth and sprout longevity are usually greater under sunny than shady conditions (Lu et al., 2020). Sprout regeneration is common in forest ecosystems (del Tredici, 2001) and in the regeneration of some rare and endangered plant populations (Du et al., 2018). Tilia cordata populations in northern England, for example, can last for thousands of years through sprouting regeneration (Pigott, 1989). Du et al. (2018) reported that sprouting plays an important role in regeneration of the Magnolia sinostellata population in China. Most research on persistence of reintroduced plants has focused on the importance of safe sites, seed and seedling banks, dispersal, and germination ( $\mathrm{Lu}$ et al., 2020). The role of sprouting of $S$. huangmeiensis as a form of persistence in conservation and management of plant species has mostly been neglected. Sprouts are resistant to disturbance and catastrophe, can tolerate long periods with little or no recruitment, and tend to preserve genetic diversity. According to an earlier study, populations of sprouting plants experiencing the loss of pollinators and dispersers can persist for long periods (Bond and Midgley, 2001).

\section{Conclusion}

Sinojackia huangmeiensis is rare and endangered because of human disturbance, its narrow distribution, low genetic diversity, limited dispersal by animals, and low germination rate. $S$. huangmeiensis has a wide range of light intensity preference. The maximum photosynthetic rate of reintroduced plants is higher than that of wild plants. Water-use efficiency of wild plants is higher than that of reintroduced plants. $S$. huangmeiensis can propagate via seeds and sprouts. Although the sprout leaves are less ecologically adaptable than trunk leaves, the ecological adaptability of the trunk and sprout leaves is complementary and thereby increases overall plant adaptability and persistence. As a plant that can grow under a wide range of light conditions and that produces both trunks and sprouts, S. huangmeiensis has a potentially wide distribution area and can adapt, at least to some degree, to global climate change. In the future, $S$. huangmeiensis can be effectively protected through in situ conservation, ex situ conservation, and reintroduction. For its ex situ conservation and reintroduction, translocating sprouts along with the trunk should increase survival rate and persistence. Conservation translocation can also be used to overcome the plant's dispersal limitations under climate change. The reintroduction of this species requires continuous monitoring.

Acknowledgements. We thank Deputy director Guoxun Chen and Mr Nan Wang for help in the field in the Longanhu National Nature Reserve. This work was supported by Huazhong Agricultural University (No.202110504038).

\section{REFERENCES}

[1] Ahrens, G. R., Newton, M. (2008): Root dynamics in sprouting tanoak forests of southwestern Oregon. - Canadian Journal of Forest Research 38: 1855-1866. 
[2] Bond, W. J., Midgley, J. J. (2001): Ecology of sprouting in woody plants: the persistence niche. - Trends in Ecology \& Evolution 16: 45-51.

[3] Catoni, R., Gratani, L. (2013): Morphological and physiological adaptive traits of Mediterranean narrow endemic plants: The case of Centaurea gymnocarpa (Capraia Island, Italy). - Flora 208: 174-183.

[4] Del Tredici, P. (2001): Sprouting in temperate trees: A morphological and ecological review. - Botanical Review 67: 121-140.

[5] Dong, H. J., Wang, H. Y., Li, Y. L., Yu, J. J. (2020): The complete chloroplast genome sequence of Sinojackia huangmeiensis (Styracaceae). - Mitochondrial DNA Part B 5: 715-717.

[6] Du, Y. X., Wu, W. J., Ji, Z. L., Zhang, D. (2018): Analysis on morphological characters of sprouts of the endangered plant Magnolia sinostellata. - Ecological Science 37: 152156.

[7] Dubois, J.-J. B., Fiscus, E. L., Booker, F. L., Flowers, M. D., Reid, C. D. (2007): Optimizing the statistical estimation of the parameters of the Farquhar-von CaemmererBerry model of photosynthesis. - New Phytologist 176: 402-414.

[8] Gao, L., Gao, P., Li, S. S. (2018): Germplasm genetic diversity of Sinojackia huangmeiensis populations based on ISSR markers. - Molecular Plant Breeding 16(18): 6017-6022.

[9] Godefroid, S., Vanderborght, T. (2011): Plant reintroductions: the need for a global database. - Biodiversity Conservation 20: 3683-3688.

[10] Liang, Y., Wang, M., Guo, J., Zhou, S. M., Wang, L. (2007): Morphologies and structures of seedlings and their phylogenies for three species in three genera of ranunculaceae. - Acta Botanic Boreali-Occid Sinica 27: 1357-1363.

[11] Liu, H., Ren, H., Liu, Q., Wen, X. Y., Maunder, M., Gao, J. Y. (2015): The conservation translocation of threatened plants as a conservation measure in China: A review. Conservation. Biology 29: 1537-1551.

[12] Liu, M. T., Wei, X. Z., Jiang, M. X. (2018): Comparison of fruit traits between wild and ex situ populations of Sinojackia huangmeiensis. - Plant Science Journal 36: 354-361.

[13] Lu, D. L., Zhu, J. J., Wang, G. F. (2020): Resprouting of tree species: A research review. - Chinese Journal of Ecology 39: 4178-4184.

[14] Luo, M. C., Shi, Q. Z., Yang, J. J., Zhang, C. T. (2016): Study on natural population of Sinojackia huangmeiensis in Hubei Province. - Journal of Anhui Agricultural Sciences 44: 67-68.

[15] Maschinski, J., Haskins, K. E. (2012): Plant Reintroduction in a Changing Climate: Promises and Perils. - Island Press, Washington DC.

[16] Maunder, M. (1992): Plant reintroduction: an overview. - Biodiversity Conservation1 1: 51-61.

[17] Nijs, I., Ferris, R., Blum, H. (1997): Stomatal regulation in a changing climate: a field study using free air temperature increase (FATI) and free air $\mathrm{CO} 2$ enrichment (FACE). Plant Cell Environ 20: 1041-1050.

[18] Ouyang, K. T., Ren, H., Xu, Z. H., Wang, F. G., Zhang, Q. M., Liu, S. Z., Guo, Q. F. (2021): Habitat characteristics and population structure of Dipteris chinensis, a relict plant in China. - Applied Ecology and Environmental Research 19(3): 1939-1951.

[19] Pigott, C. D. (1989): Factors controlling the distribution of Tilia cordata Mill at the northern limits of its geographical range. - New Phytologist 112: 1175-121.

[20] Qin, H., Zhao, N. L. (2017): Evaluating the threat status of higher plants in China. Biodiversity Science 25: 689-695.

[21] Ren, H. (2020): Conservation and Reintroduction of Rare and Endangered Plants in China. - Springer, Singapore, 233p.

[22] Ren, H., Liu, H., Wang, J., Yuan, L. L., Cui, X. D., Zhang, Q. M., Fu, L., Chen, H. F., Zhong, W. C., Yang, K. M., Guo, Q. F. (2016): The use of grafted seedlings increases the 
success of conservation translocations of Manglietia longipedunculata (Magnoliaceae), a critically endangered tree. - Oryx 50: 437-445.

[23] Ren, H., Yi, H. L., Zhang, Q. M., Wang, J., Wen, X. Y., Guo, Q. F., Liu, H. (2019): Morphological, anatomical and physiological traits of Euryodendron excelsum as affected by conservation translocation (augmentation vs. conservation introduction) in South China. - Photosynthetica 57: 217-225.

[24] Ruan, Y. M., Zhang, J. J., Yao, X. H., Huang, H. W., Ge, J. W. (2012): Genetic diversity and fine-scale spatial genetic structure of different life history stages in a small, isolated population of Sinojackia huangmeiensis (Styracaceae). - Biodiversity Science 20: 460469.

[25] Seddon, P. J. (2010): From reintroduction to assisted colonization: moving along the conservation translocation spectrum. - Restoration Ecology 18: 796-802.

[26] Sharrock, S., Wyse Jackson, P. (2017): Plant conservation and the sustainable development goals: a policy paper prepared for the global partnership for plant conservation. - Annual. Mossouri Botanical Garden 102: 290-302.

[27] Soudzilovskaiaa, N. A., Elum, T. G., Onipchenko, V. G., Shidakov, I., Salpagarova, F. S., Khubiev, A. B., Tekeev, D. K., Cornelissen, J. H. C. (2013): Functional traits predict relationship between plant abundance dynamic and long-term climate warming. - PNAS 110: 18180-18184.

[28] Taylor, G., Canessa, S., Clarke, R. H., Ingwersen, D., Ewen, D. J. G. (2017): Is reintroduction biology an effective applied science? - Trends in Ecology \& Evolution 32: 873.

[29] Wang, Y., Shao, L., Wang, J., Ren, H., Liu, H., Zhang, Q. M., Guo, Q. F., Chen, X. W. (2016): Comparison of morphological and physiological characteristics in two phenotypes of a rare and endangered plant, Begonia fimbristipula Hance. Photosynthetica 54: 381-389.

[30] Wang, S. T., Wu, H., Liu, M. T., Jiang, M. X. (2018): Community structure and dynamics of a remnant forest dominated by a plant species with extremely small population (Sinojackia huangmeiensis) in central China. - Biodiversity Science 26: 99109.

[31] Wang, S. T., Xu, Y. Z., Yang, T., Jiang, M. X. (2019): Impacts of microhabitats on leaf functional traits of the wild population of Sinojackia huangmeiensi. - Biodiversity Science 28: 277-288.

[32] Wei, X. Z., Liu, M. T., Wang, S. T., Jiang, M. X. (2018): Seed morphological traits and seed element concentrations of an endangered tree species displayed contrasting responses to waterlogging induced by extreme precipitation. - Flora 246: 19-25.

[33] Yang, J., Cai, L., Liu, D. T., Chen, G., Sun, W. B. (2020): China's conservation program on plant species with extremely small populations (PSESP): progress and perspectives. Biological Conservation 244: 108535.

[34] Zhao, J., Tong, Y. Q., Ge, T. M., Ge, J. W. (2016): Genetic diversity estimation and core collection construction of Sinojackia huangmeiensis based on novel microsatellite markers. - Biochemical Systematics and Ecology 64: 74-80.

[35] Zhang, J. J., Ye, Q. G., Yao, X. X., Zhang, S. J., Huang, H. W. (2008): Preliminary studies on the floral biology, breeding system and reproductive success of Sinojackia huangmeiensi, an endangered plant in a fragmented habitat in Hubei Province, China. Chinese Journal of Plant Ecology 32: 743-750. 